OPEN

SUBJECT AREAS:

CHEMICAL BIOLOGY

MICROBIOLOGY

Received

2 April 2014

Accepted

19 August 2014

Published

25 September 2014

Correspondence and requests for materials should be addressed to X.L.L. (seedling@cau. edu.cn)

\section{Activity of the novel fungicide SYP-ZO48 against plant pathogens}

\author{
Fengping Chen ${ }^{1,2}$, Ping Han ${ }^{2,3}$, Pengfei Liu ${ }^{2}$, Naiguo $\mathrm{Si}^{4}$, Junli Liu ${ }^{4} \&$ Xili Liu ${ }^{2}$
}

'Key Laboratory of Plant Virology of Fujian Province, Institute of Plant Virology, Fujian Agriculture and Forestry University, Fuzhou, 350002, China, ${ }^{2}$ Department of Plant Pathology, China Agricultural University, Beijing 100193, China, ${ }^{3}$ Beijing Research Center for Agricultural Standards and Testing, Beijing 100097, China, ${ }^{4}$ State Key Laboratory of the Discovery and Development of Novel Pesticide, China ShenYang Research Institute of Chemical Industry, Shenyang 110021, China.

In in vitro tests with 18 plant pathogens, the fungicide 3-[5-(4-chlorophenyl)-2,3-dimethyl-3-isoxazolidinyl] pyridine (SYP-Z048) was highly effective on inhibiting mycelial growth of various ascomycota and basidiomycota, with $\mathrm{EC}_{50}$ values ranging from 0.008 to $1.140 \mu \mathrm{g} / \mathrm{ml}$. SYP-Z048 had much weaker activity against growth of oomycota with $\mathrm{EC}_{50}$ values $>100 \mu \mathrm{g} / \mathrm{ml}$. In a second in vitro test with Monilinia fructicola isolates, SYP-Z048 inhibited mycelial growth $\left(\mathrm{EC}_{50}=0.013 \mu \mathrm{g} / \mathrm{ml}\right)$, germ tube elongation $\left(\mathrm{EC}_{50}\right.$ $=0.007 \mu \mathrm{g} / \mathrm{ml}$ ), and sporulation but did not affect spore germination. In a detached pear fruit assay inoculated with M. fructicola isolates, SYP-Z048 showed protective and curative activity. Field tests indicated that SYP-Z048 was an efficacious fungicide for control of brown rot disease in two peach orchards. When applied to a single spot on a tomato leaflet in a compound leaf, SYP-Z048 suppressed the growth of Botrytis cinerea isolates on the rest 4 leaflets, indicating that the fungicide has systemic movement in plant tissues. These results indicate that SYP-Z048 has potential for management of brown rot causing by $M$. fructicola and other diseases caused by ascomycota and basidiomycota.

I ungi are among the crop pests that reduce crop yield and food quality, and they also can produce toxic compounds that make the produce harmful for consumers. Damage caused by plant-pathogenic fungi is often controlled by the application of fungicides. Currently more than $80 \%$ of the fruit and vegetable crops grown in the U.S. receive at least one fungicide application every season; if the crops were left untreated, the yields of most fruit and vegetables would reduce 50 to 95 percent $^{1}$. Fungicides are estimated to increase farm income in the U.S. by nearly $\$ 13$ billion annually ${ }^{1}$. In China, pesticide application has been increasing annually. Fungicides have become an integral part of efficient food production in China and other countries.

Many fungicides that target different pathogens and diseases have been reported ${ }^{2-5}$, but because of problems relating to toxic residues, disease resurgence and pathogen resistance ${ }^{6-10}$, the use of many fungicides is restricted. Therefore, researchers have been searching for fungicides with low toxicity, high selectivity, and high activity against fungal strains that are resistant to other fungicides.

SYP-Z048, 3-[5-(4-chlorophenyl)-2,3-dimethyl-3-isoxazolidinyl] pyridine, a mixture of two diasteromers (Fig. 1), is a novel fungicide developed for control of plant-pathogenic fungi by China Shenyang Research Institute of Chemical Industry in 1997. SYP-Z048 have been registered for control of grey mold caused by Botrytis cinerea on tomato in China as Junsiqi (25\% EC, China Shenyang Research Institute of Chemical Industry, Shenyang, China) ${ }^{11}$. SYP-Z048 inhibits ergosterol synthesis in B. cinerea ${ }^{12}$ and has been demonstrated to be a sterol $14 \alpha$-demethylase inhibitor (DMI) ${ }^{13}$.

DMI fungicides have been playing an important role in chemical control of many diseases since they were developed in 1970s, providing high efficacy against a broad spectrum of fungal pathogens. DMIs consist of many structurally heterogeneous compounds, belonging to different subclasses. The subclasses of imidazole and triazole are among the most widely used fungicides, as well as pyridines, such as pyrifenox ${ }^{14}$ and buthiobate ${ }^{15}$. SYPZ048 is a pyridine derivative that includes a isoxazolidine ring.

It has been documented SYP-Z048 has highly activity on M. fructicola, the causal agent of brown rot. The mean $\mathrm{EC}_{50}$ values for baseline population of $M$. fructicola is $0.017 \mu \mathrm{g} / \mathrm{ml}^{13}$, which is similar to the values for propiconazole $(0.03 \mu \mathrm{g} / \mathrm{ml})^{16}$ and tebuconazole $(0.016 \mu \mathrm{g} / \mathrm{ml})^{17}$. The antifungal activity of SYP-Z048 against other plantpathogenic fungi or on $M$. fructicola causing brown rot in field, however, is unknown.

The objectives of this study were to determine: (a) the in vitro antifungal activity of SYP-Z048 against 18 plantpathogenic fungi; (b) the fungicidal activities of SYP-Z048 on different developmental stages of M. fructicola; (c) 


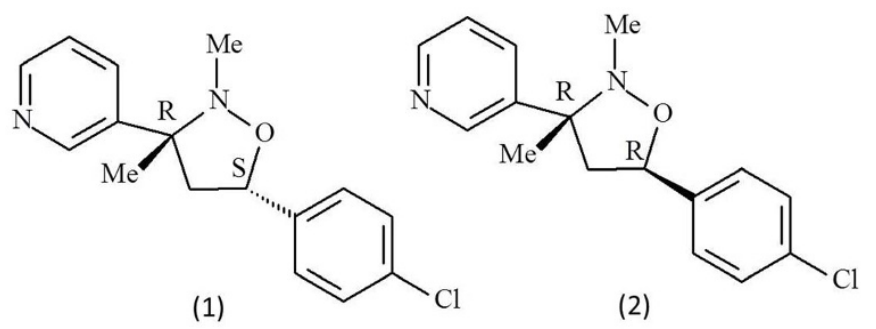

Figure $1 \mid$ Structure of SYP-Z048 used in the experiments, a mixture of two stereoisomers: 3-[(3R, 5S)-5-(4-chloro-phenyl)-2,3-dimethyl-3isoxazolidinyl] pyridine (1) and its (3R, 5R)-isomer (2), drawn by Fengping Chen.

the preventative and curative activities of SYP-Z048 by detach fruits assay and control efficacy in field on brown rot and (d) systemic activity in tomato leaves.

\section{Results}

In vitro activity of SYP-Z048 against 18 plant pathogens. SYP-Z048 inhibited the in vitro mycelial growth of many plant-pathogenic fungi, including ascomycota and basidiomycotac (Table 1) with $\mathrm{EC}_{50}$ values of $0.008-1.140 \mu \mathrm{g} / \mathrm{ml})$. In contrast, SYP-Z048 was much less effective against oomycota with $\mathrm{EC}_{50}$ values $>100 \mu \mathrm{g} / \mathrm{ml}$ (Table 1).

Effect of SYP-Z048 on the different developmental stages of $M$. fructicola. SYP-Z048 substantially inhibited mycelial growth, germ tube elongation, and sporulation of $M$. fructicola (Table 2). The $\mathrm{EC}_{50}$ values were 0.013 and $0.001 \mu \mathrm{g} / \mathrm{ml}$ for mycelial growth and germ tube elongation, respectively. The inhibition activity of SYP-Z048 was greater for initial germ tube elongation than for mycelial growth. Spore production was significantly inhibited by SYP-Z048 when the concentration was $>0.02 \mu \mathrm{g} / \mathrm{ml}$. Spore germination was not affected by SYP-Z048 (Table 2).

Protective and curative activity of SYP-Z048 on detached pear fruit. Whether applied $24 \mathrm{~h}$ before inoculation (protective activity) or $24 \mathrm{~h}$ after inoculation (curative activity), SYP-Z048 provided substantial control of $M$. fructicola on pear fruit (Table 3). The efficacy for protective and curative activity was $89.3 \%$ and $85.2 \%$, respectively (Table 3 ). Comparison of disease incidence and lesion

\begin{tabular}{|llcc}
\hline Table 1 | In vitro inhibition of plant pathogens by SYP-ZO48 \\
Organism & Species & $\begin{array}{c}\text { Correlation* } \\
\text { coefficient }\end{array}$ & $\begin{array}{c}\mathrm{EC}_{50} \\
(\mu \mathrm{g} / \mathrm{ml})\end{array}$ \\
\hline Ascomycota & Gibberella zeae & 0.976 & 0.047 \\
& G. fujikuroi & 0.991 & 0.044 \\
& Fusarium oxysporum & 0.994 & 0.315 \\
& Valsa mali & 0.978 & 0.067 \\
& Physalospora piricola & 0.996 & 0.033 \\
& Monilinia fructicola & 0.989 & 0.013 \\
& Sclerotinia sclerotiorum & 0.995 & 0.009 \\
& Gaeumannomyces graminis & 0.995 & 0.081 \\
& Cladosporium cucumerium & 0.988 & 0.046 \\
& Cochliobolus lunatus & 0.986 & 0.008 \\
& Botrytis cinerea & 0.976 & 0.306 \\
& Magnaporthe oryzae & 0.989 & 1.140 \\
& Passalora fulva & 0.986 & 0.126 \\
& Alternaria solani & 0.992 & 0.418 \\
Basidiomycota & Ceratobasidium cerealis & 0.988 & 0.573 \\
& Sphacelotheca reiliana & 0.969 & 0.079 \\
Oomycota & Pythium aphanidermatum & - & $>100$ \\
& Phytophthora capsici & - & $>100$
\end{tabular}

*Correlation between the probability value transformed by percentage of inhibition relative to the control (without fungicide) and the concentration (log transformed) of the fungicide.

\begin{tabular}{|c|c|c|c|c|}
\hline $\begin{array}{l}\text { SYP-Z048 } \\
\text { concentration } \\
(\mu \mathrm{g} / \mathrm{ml})\end{array}$ & $\begin{array}{l}\text { Inhibition of } \\
\text { mycelial } \\
\text { growth (\%) }\end{array}$ & $\begin{array}{c}\text { Inhibition of } \\
\text { germ tube } \\
\text { elongation (\%) }\end{array}$ & $\begin{array}{c}\text { Spore } \\
\text { production } \\
10^{4} \text { spores/ } \\
\mathrm{cm}^{2}\end{array}$ & $\begin{array}{c}\text { Spore } \\
\text { germination } \\
(\%)\end{array}$ \\
\hline 0.00 & - & - & $15.94 a^{*}$ & $85.6 a$ \\
\hline 0.005 & 27.7 & 65.5 & $14.91 \mathrm{ab}$ & $85.6 a$ \\
\hline 0.01 & 48.9 & 68.7 & $12.99 \mathrm{ab}$ & $85.5 a$ \\
\hline 0.02 & 56.8 & 73.1 & $7.12 \mathrm{bc}$ & $83.0 a$ \\
\hline 0.03 & 71.7 & 74.3 & $1.15 c$ & $85.0 a$ \\
\hline 0.06 & 81.6 & 81.1 & $0.33 c$ & $84.8 a$ \\
\hline $\mathrm{EC}_{50}$ & 0.013 & 0.001 & - & - \\
\hline
\end{tabular}

area after inoculation of $M$. fructicola for 3 days indicated that the fungicide was slowing down disease progression.

Control efficacy of SYP-Z048 on brown rot in field. Significant differences among fungicides treatments were observed in both peach orchards, (Fig. 2). All fungicides treatments were statistically superior to water control $(\mathrm{P}<0.05)$. SYP-Z048 treatment controlled brown rot significantly better than thiophonate-methyl and propineb when the concentration was $>100 \mathrm{~g} / \mathrm{L}$ in both locations. Compared to fenbuconazole at same dose, lower efficacy was observed with SYP-Z048 application at the Liaoning location whereas no difference among these treatments was observed at the Shandong location.

Systemic activity of SYP-Z048 in tomato leaves. In the first experiment concerning systemic activity of SYP-Z048, the fungicide SYPZ048 inhibited $B$. cinerea on the leaflet where the fungicide was applied (the fourth leaflet) (Fig. 3) and suppressed lesion developing on the other four leaflets, although the fungicide was less effective on the untreated leaflets than on the treated leaflet (Fig. 4).

In the second experiment concerning movement of SYP-Z048 in tomato leaves, inhibition of $B$. cinerea on the upper epidermis side of the leaflet was similar to inhibition on the lower epidermis side of the leaflet when the fungicide was added on the opposite side of the leaflet (Fig. 5).

\section{Discussion}

SYP-Z048 is a novel fungicide, being both pyridine derivative and also carrying a isoxazolidine ring. Both groups are effective on some pathogens. The combination of two active groups in SYP-Z048 would make this compound behave specially. Isoxazolidine or oxazole derivatives have been synthesized for antitumor, antiamoebic, antimicrobial, herbicidal, and fungicidal activities ${ }^{18-23}$; many are effective against human pathogens. Activity against plant pathogens by other oxazolidinones and oxazolidine-diones involves inhibition of RNA polymerase I and cytochrome $b^{24,25}$. Pyridine fungicides possess different modes of action according to the specific fungicide.

Table 3 | Protective and curative effect of SYP-Z048 on brown rot in detached pears after inoculation of $M$. fructicola for 3 days

\begin{tabular}{lccc} 
Treatment & $\begin{array}{c}\text { Disease } \\
\text { Incidence }(\%)\end{array}$ & $\begin{array}{c}\text { Lesion area } \\
\left(\mathrm{mm}^{2}\right)\end{array}$ & $\begin{array}{c}\text { Control } \\
\text { Efficacy }(\%)\end{array}$ \\
\hline Water spray with inoculation & $100 a^{*}$ & $193.7 \mathrm{a}$ & - \\
Curative treatment & $65.1 \mathrm{~b}$ & $28.7 \mathrm{~b}$ & 85.2 \\
Protective treatment & $66.3 \mathrm{~b}$ & $20.8 \mathrm{~b}$ & 89.3 \\
Water spray without inoculation & Oc & Oc & - \\
\hline *Means in a column followed by different letters are significantly different $(\mathrm{P}<0.05)$.
\end{tabular}




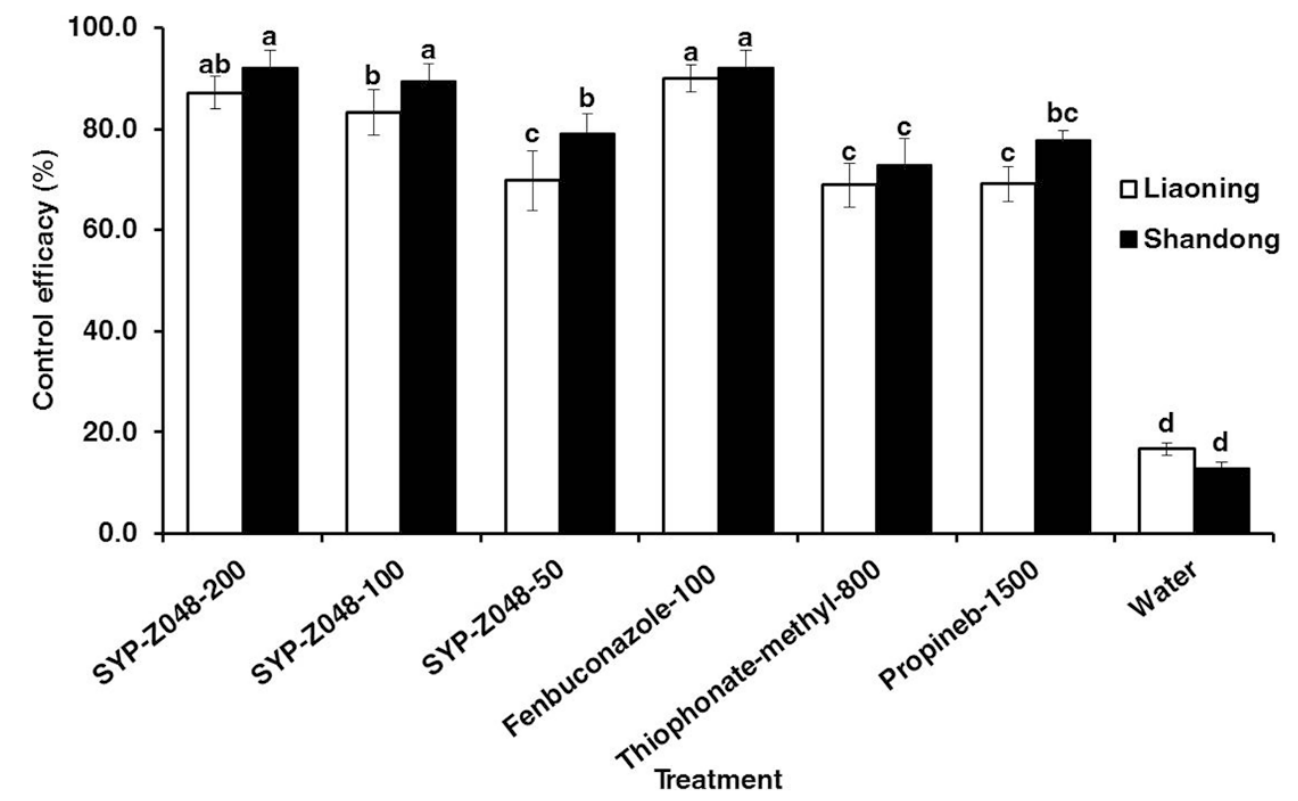

Figure 2 Efficacy of SYP-Z048 and other fungicides for brown rot disease control in peach orchards in Liaoning and Shandong province in China in 2013.

Most of pyridines are respiration inhibitors, for example succinate dehydrate inhibitors boscalid and fluopyram ${ }^{5}$ and succinate-cytochrome $\mathrm{c}$ reductase inhibitor pyribencarb ${ }^{26}$; some pyridines are $14 \alpha$-demethylase inhibitors such as buthiobate ${ }^{15}$ and pyrifenox ${ }^{14}$; dipyrithione is response to lipopolysaccharide ${ }^{27}$ and fluopicolide is involve in modification of the cellular localization of a spectrin-like protein $^{28}$. SYP-Z048 has typical $14 \alpha$-demethylase inhibitor activity ${ }^{13}$, which should be a novel member of the demethylation inhibitors of ergosterol biosynthesis, but whether the activity of SYP-Z048 also results from other mechanism is not clear yet.

The lack of inhibition on M. fructicola spore germination supports the modes of action of SYP-Z048 which was implied as a DMI fun-

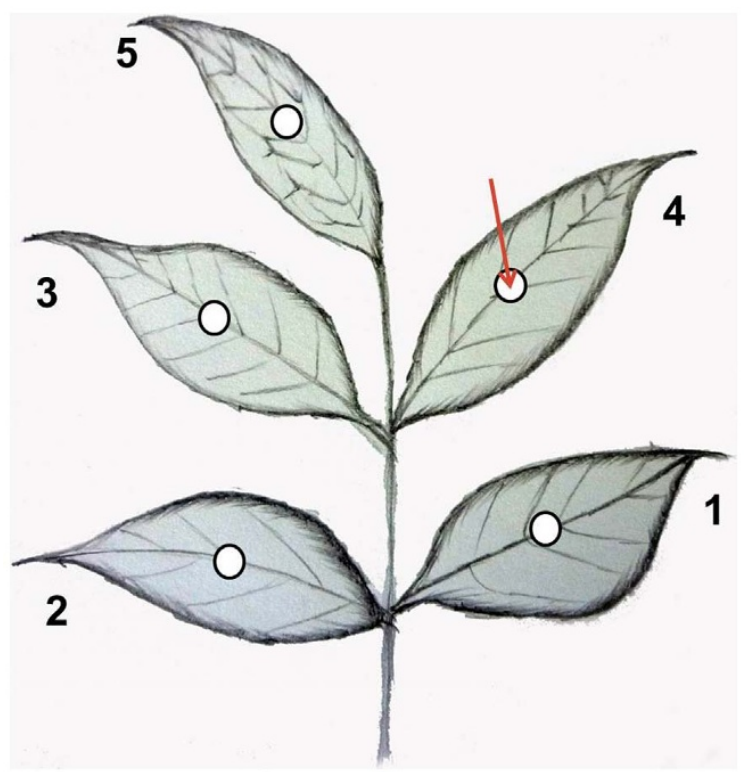

Figure 3 Schematic of a tomato leaf (with five numbered leaflets, created by Fengping Chen) used in the experiments to determine systemic activity of SYP-Z048. A drop of fungicide was added to the fourth leaflet (arrow) before leaflets were inoculated with mycelium plug (circles) colonized by B. cinerea. See Methods section for additional details. gicide $^{13}$. In general, DMI fungicides are known to inhibit hyphal growth strongly rather than spore germination ${ }^{29}$. For example, DMIs doesn't affect the urediniospore germination of Puceinia hemerocallidis ${ }^{30}$ and conidium germination of Spilocaea oleagina ${ }^{31}$. But in some pathogens, it is effective on spore germination ${ }^{32,33}$. The behavior observed for DMIs in pathogens differs due to the stage of starting sterol biosynthesis. Conidia of some species are able to synthesize sterols in the early stage of germination, whereas other initiate sterol synthesis at the very end of the germ tube phase ${ }^{33}$.

SYP-Z048 has potential for control of diseases caused by 16 plantpathogenic ascomycota and basidiomycota fungi but not the oomycota. According to our in vitro experiment, the $\mathrm{EC}_{50}$ values for SYP-Z048 $<1 \mu \mathrm{g} / \mathrm{ml}$ to all experimental fungi except $M$. oryzae. The data collected under controlled conditions might not be the same as field study, but it reflects the real efficacy to some extent. For example, $M$. fructicola was inhibited strongly by SYP-Z048 in vitro $\left(\mathrm{EC}_{50}=0.013 \mu \mathrm{g} / \mathrm{ml}\right)$, and in consistent, brown rot caused by M. fructicola was controlled efficaciously in the field with the application dose of $100 \mu \mathrm{g} / \mathrm{ml}$ (The efficacy $>80 \%$ ).

SYP-Z048 exhibits substantial activity on brown rot of stone fruit, caused by $M$. fructicola. M. fructicola is a world widespread pathogen, including Asia, Europe, Africa, North America, Central America, as well as South America and Oceania ${ }^{34}$. The fungus can cause not only fruit rot but also blossom blight and twig canker, especially causing damage in postharvest fruit ${ }^{35,36}$. The most effective management

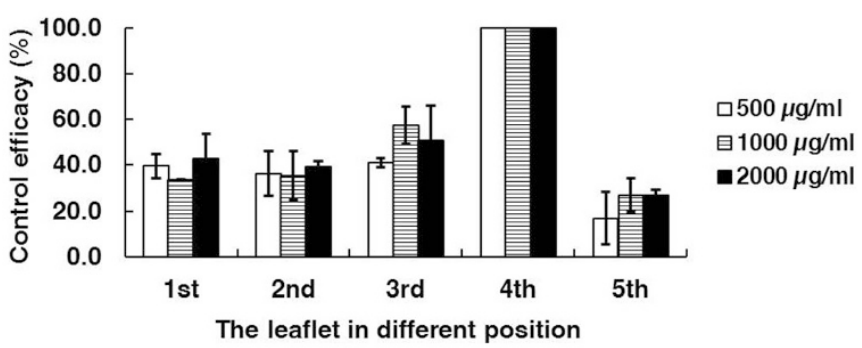

Figure $4 \mid$ The efficacy of SYP-Z048 against $B$. cinerea after 2 days inoculation when the fungicide was applied to the fourth leaflet and the fungus was inoculated to all five leaflets on a tomato leaf. See Fig. 3 and the text for more details. 


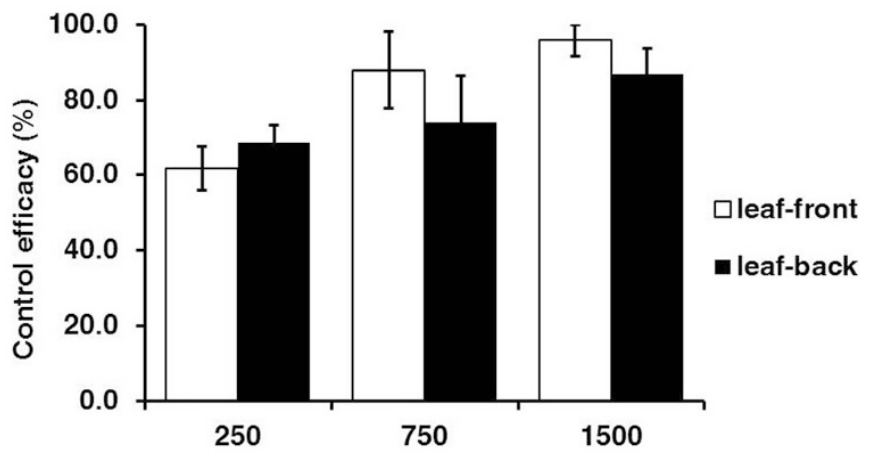

Concentration of SYP-Z048 $(\mu \mathrm{g} / \mathrm{ml})$

Figure 5 | The efficacy of SYP-Z048 against $B$. cinerea after 2 days inoculation when the fungicide was applied to the upper epidermis (leaffront) or lower epidermis (leaf-back) of a tomato leaflet and the fungus was inoculated to the other side of the same leaflet.

approaches are pre-harvest fungicide applications. Although resistance to benzimidazoles ${ }^{37}$, dicarboxamides ${ }^{38}$, succinate dehydrogenase inhibitors (SDHIs) and quinone outside inhibitor fungicides (QoIs) ${ }^{39}$ has been reported in M. fructicola, SYP-Z048 is not crossresistant to compounds belonging to those classes $^{13}$. The comparison of efficacy in two peach orchards showed that SYP-Z048 was more efficacious than thiophonate-methyl (a representative of benzimidazoles) and propineb (a protective fungicide) in this study, even the application concentration was 8 times and 15 times less, respectively. All the facts taken together suggest that SYP-Z048 is a fungicide with practical significance in brown rot management.

SYP-Z048 possesses both protective and curative fungicidal activity. Such fungicides are key components of modern agriculture due to their ability of preventing disease expanding. The detached fruit assay showed SYP-Z048 controlled brown rot well when applied before inoculation, but also showed high efficacy when applied after inoculation which is not significantly different from the pre-treatment. The movement of SYP-Z048 in plant tissue was confirmed using the compound leaf of tomato. The data we obtained indicated that SYP-Z048 could penetration into leaflet and move acropetally, horizontally, and basipetally in plant, and also moved through the leaflet tissues. after application.

In conclusion, SYP-Z048 has substantial in vitro activity against a very broad spectrum of plant pathogenic fungi. The fungicide is a systemic fungicide with both protective activity and curative activity against brown rot disease. The novel structure fungicide SYP-Z048 may be expected to be an effective agrochemical agent in plant disease management.

\section{Methods}

Media, fungicides, and pathogens. Potato dextrose agar (PDA medium) was used for the routine culture of the fungi and contained $200 \mathrm{~g}$ of potato, $15 \mathrm{~g}$ of glucose, and $12 \mathrm{~g}$ of agar in $1 \mathrm{~L}$ of sterile deionized water. The medium was autoclaved for $20 \mathrm{~min}$ at $121^{\circ} \mathrm{C}$. Water agar was used for the spore germination and tube elongation tests and contained $12 \mathrm{~g}$ of agar in $1 \mathrm{~L}$ of sterile deionized water, without sterilization. The chemicals were purchased from Syngenta China Ltd. (Beijing). The same batch of medium was used for all replicates within each experiment to reduce variability.

The fungicide SYP-Z048 (84\%) was kindly provided by China ShenYang Research Institute of Chemical Industry. The chemical was dissolved in methanol and diluted to $10 \mathrm{mg} / \mathrm{ml}$ as a stock solution, which was stored at $4{ }^{\circ} \mathrm{C}$ in the dark to preserve fungicide activity. For each assay on PDA plate, the stock solution was diluted to working concentrations with sterile deionized water. In all cases, the final amount of solvent never exceeded $0.1 \%$ in treated and control samples. The formulations of SYP-Z048 (25\% Junsiqi EC) was provided by Shenyang Sciencreat ChemicalsCo.,Ltd; fenbuconazole (24\% Yingde SC), thiophonate-methyl (70\% Jiajiliujunling WP) and propineb (70\% bingsenxin WG) were purchased from Dow AgroScience, Jiangsu Rotam Chemistry Co., Ltd., and NantongBaoye Chemical Co., Ltd., respectively.

The activity of SYP-Z048 was tested against the following plant-pathogenic fungi: Gibberella zeae, G. fujikuroi, Fusarium oxysporum, Valsa mali, Physalospora piricola, M. fructicola, Sclerotinia sclerotiorum, Gaeumannomyces graminis, Cladosporium cucumerium, Cochliobolus lunatus, Botrytis cinerea, Magnaporthe oryzae, Passalora fulva, Alternaria solani, Ceratobasidium cerealis, Sphacelotheca reiliana, Pythium aphanidermatum and Phytophthora capsici. S. reiliana was cultured in Richard's liquid medium $\left(10.0 \mathrm{~g}\right.$ of $\mathrm{KNO}_{3}, 5.0 \mathrm{~g}$ of $\mathrm{KH}_{2} \mathrm{PO}_{4}, 2.5 \mathrm{~g}$ of $\mathrm{MgSO}_{4} \cdot 7 \mathrm{H}_{2} \mathrm{O}, 0.02 \mathrm{~g}$ of $\mathrm{FeCl}_{3}, 30.0 \mathrm{~g}$ of glucose and $1 \mathrm{~L}$ of sterile deionized water) at $20^{\circ} \mathrm{C}$. The other fungi were cultured on PDA at $25^{\circ} \mathrm{C}$

Inhibitory activity of SYP-Z048 in vitro. The stock solution of SYP-Z048 in methanol was diluted serially in autoclaved PDA (cooled to around $50^{\circ} \mathrm{C}$ ) to achieve final concentrations according to preliminary test (data not show). Before it solidified, the PDA plus fungicide was added to 9-cm diameter Petri plates, with three replicate plates per concentration. Control plates contained PDA without fungicide but with corresponding concentrations of methanol $(\leq 0.1 \%)$. For each of the 18 test fungi listed in Table 1, except $S$. reiliana, a mycelium plug $(5 \mathrm{~mm})$ was transferred from the leading edge of an actively growing colony on PDA to the dishes amended with 0 to different concentrations fungicide, with percentage inhibition from $10 \%$ to $90 \%$. The dishes were incubated at $25^{\circ} \mathrm{C}$ in darkness. When the colony in control plates (without fungicide) had covered $75 \%$ of the agar surface, the diameter of all colonies of that microorganism were measured. The percentage of inhibition of radial growth was calculated. The tests were replicated three times for each microorganism.

The effect of SYP-Z048 on growth of S. reiliana, which does not grow on PDA, was determined with the ELISA plate turbidity method. S. reiliana teliospores (10 $\mathrm{mg})$ collected from diseased corn were suspended in $10 \mathrm{ml}$ of $0.03 \%$ Tween 20 for $4 \mathrm{~h}$. The suspension was centrifuged at $4000 \mathrm{~g}$ for $10 \mathrm{~min}$. The pelleted teliospores were added to a $0.25 \% \mathrm{KMnSO}_{4}$ solution. After $25 \mathrm{~min}$, sterilized water was added and then centrifuged again. The pelleted teliospores were immersed in $0.05 \mathrm{M} \mathrm{HCl}$ for $6 \mathrm{~h}$ before they were mixed into Richard's medium adjusted to approximately $10^{5}$ teliospores/ml. Liquid containing $75 \mu \mathrm{l}$ teliospores suspension and $75 \mu \mathrm{l} \mathrm{SYP-Z048} \mathrm{of}$ each concentration were added to each well of ELISA plates. The plates were incubated at $28^{\circ} \mathrm{C}$ on a rotary shaker $(120 \mathrm{r} / \mathrm{min})$ in darkness for $84 \mathrm{~h}$. There were three wells per fungicide concentration, and the experiment was performed twice. The transmittance and optical density at $650 \mathrm{~nm}\left(\mathrm{OD}_{650}\right)$ of the suspension in each well was measured with a microplate reader (Bio-rad model550) and inhibition based on differences in optical densities between fungicide treatments and controls. The median effective concentration value $\left(\mathrm{EC}_{50}\right)$ was calculated by regressing the percentage inhibition (probability value transformed) against the logarithm value of fungicide concentration (log transformed). Regression analysis was performed with Microsoft Excel 2007

Effect of SYP-Z048 on different developmental stages of M. fructicola. Effect of SYP-Z048 on mycelial growth of $M$. fructicola isolate was measured as described above. The fungicide concentrations were $0,0.005,0.01,0.02,0.03$, and $0.06 \mathrm{mg} / \mathrm{l}$. After colony diameters were measured, the cultures were used to determine the effect of SYP-Z048 on spore production. In cultures with $<0.02 \mathrm{mg} / \mathrm{l}$, six colonized agar plugs, $5 \mathrm{~mm}$ in diameter, were excised from each replicate plate; the selected plugs were taken along the radius from the center of the cultureto the margin of the colony. In plates with higher concentrations of fungicide, the colony was too small to collect plugs along the radius, therefore a single plug was collected. The plugs from each plate were put into a $15-\mathrm{ml}$ tube with $2.0 \mathrm{ml}$ of sterile deionized $\mathrm{H}_{2} \mathrm{O}$, agitated with a sterile needle, and shaken for $5 \mathrm{~min}$ with a laboratory vortex mixer. Spores were counted using a haemocytometer. Spore production was expressed as the number of spores per $\mathrm{mm}^{2}$ of colony area.

To determine the effect of SYP-Z048 on spore germination and germ tube elongation, spores were harvested from a colony of $M$. fructicola isolate growing on PDA without fungicide by adding sterile deionized water to the plate and agitating The spore suspension was adjusted to approximately $10^{6}$ spores $/ \mathrm{ml}$. One hundred $\mu \mathrm{l}$ of the spore suspension was spread on water agar in $9 \mathrm{~cm}$ diam petri dishes containing $0,0.005,0.01,0.02,0.03$ and $0.06 \mathrm{ug} / \mathrm{ml}$ SYP-Z048. Germination was measured after $6 \mathrm{~h}$ at room temperature in the dark by examining 100 spores in three locations on the petri dish at $100 \times$ magnification. A spore was scored as germinated if the germ tube had reached at least the full length of the spore. The dishes were then incubated for an additional $4 \mathrm{~h}$ under the same conditions and germ tube length was measured on 60 germinated spores per dish at $400 \times$ magnification using Image-Pro Plus 5.0 software. Three replicate plates were used for each concentration of SYPZ048.

Preventive and curative activity of SYP-Z048 on pear fruit. The methods for determining the preventive and curative activity of $M$. fructicola on pear fruits were similar to those described previously ${ }^{40,41}$. The pears of "Fengshui" variety were purchased from a supermarket. Before inoculation, pears were kept at $23^{\circ} \mathrm{C}$ overnight and were rinsed with tap water and air-dried. After the pears were peeled and cut in half, they were placed in a plastic box with a wet filter paper at the bottom, cut side facing down, and were then wounded with a sterile needle on the peeled but uncut surface (six wounds per fruit half). Each wounded site was inoculated with $10 \mu \mathrm{l}$ of an M. fructicola spore suspension $\left(5 \times 10^{6}\right.$ conidia/ml $)$ obtained from other pears that had been previously inoculated and infected with M. fructicola. SYP-Z048 $(200 \mu \mathrm{g} /$ $\mathrm{ml}$ ) was applied either $24 \mathrm{~h}$ before the fruit was inoculated (protective treatment) or $24 \mathrm{~h}$ after the fruit was inoculated (curative treatment); the fungicide was applied to runoff with a fine-mist sprayer. Two control treatments were included. In one control (positive control), fruit were inoculated with $M$. fructicola $24 \mathrm{~h}$ after spraying with sterile water. In the other control (negative control), wounded fruit were sprayed with water but not inoculated. The moisture boxes were sealed with clear plastic and 
arranged randomly in climate control chamber maintained at $23^{\circ} \mathrm{C},>80 \% \mathrm{RH}$, and a 12 -h photoperiod. After 4 days, the number of infected wounds and the diameter of the lesions around the wounds were recorded. The experiment was performed twice with 3 replicates per experiment. Each replicate consisted of 12 inoculations.

Control efficacy of SYP-Z048 on brown rot in field. To assess the efficacy of SYPZ048 for control of brown rot in the field, the fungicides of SYP-Z048 (25\% Junsiqi EC), fenbuconazole (24\% Yingde SC), thiophonate-methyl (70\% Jiajiliujunling WP) and propineb (70\% bingsenxin WG) were applied to trees in two orchards. Three concentrations of SYP-Z048 were tested (50,100 and $200 \mathrm{~g} / \mathrm{L})$ and compared to fenbuconazole, thiophonate-methyl and propineb applied at 100, 800, and $1500 \mathrm{~g} / \mathrm{L}$, respectively. Control treatments were trees sprayed with water. Treatments were replicated four times in a randomized block with four trees per replication. All fungicides were applied by sprayer to runoff four times before harvest. 'Jinlu' peach trees were treated on 6 May, 20 May, 4 June and 18 June 2013 in Liaoning province in China. 'Baifeng' peach trees were treated on 29 April, 16 May, 30 May, and 15 June 2013 in Shandong province in China. When fruit were at commercial shipping maturity, a sample consisting of 150 fruit, was randomly harvested from each tree and the total number of diseased fruit was counted. Disease incidence was expressed as percentage of diseased fruit and control efficacy was express as: Control efficacy (\%) $=(1-\mathrm{A}) \times 100$, where $\mathrm{A}=$ disease incidence with fungicide treatment divided by mean disease incidence with water application.

Systemic activity of SYP-Z048 against $B$. cinerea on tomato leaves. To investigate potential movement and activity of the fungicide in acropetal, horizontal, and basipetal directions, the fungicide was applied in one spot on a tomato leaf with inoculation in the same spot and other locations in two experiments. In the first experiment, pinnately compound leaves (with five leaflets) were collected at the $3^{\text {rd }}$ leaf position from tomato (Lycopersicum esculentum Mill cv. Jiabao) plants growing in the greenhouse. The leaves were rinsed with tap water, air dried, and placed in a plastic box with wet filter paper at the bottom. In the first experiment $10-\mu \mathrm{L}$ containing $0,500,1000$, or $2000 \mu \mathrm{g} \mathrm{ml}^{-1}$ SYP-Z048 was applied as a drop to the adaxial side of the fourth leaflet (Fig. 3). The boxes were sealed with clear plastic and arranged randomly in a climate control chamber at $23^{\circ} \mathrm{C},>80 \% \mathrm{RH}$, and a $12-\mathrm{h}$ photoperiod. One day after application, a 3-mm-diam mycelium plug from the margin of an actively growing colony of $B$. cinerea on PDA was placed on the adaxial side of each of the five leaflets. After 2 days the diameter of the B. cinerea colony formed around each plug was recorded. The experiment was performed twice with three replicates per treatment. Each replicate consisted of 10 leaves.

In a second experiment, $10 \mu \mathrm{L}$ containing $0,250,750$, or $1500 \mu \mathrm{g} \mathrm{ml}^{-1} \mathrm{SYP}-\mathrm{Z} 048$ was applied to the upper epidermis side of the leaflet or lower epidermis side. After $24 \mathrm{~h}$, the leaflet was incubated as above with a 3-mm-diam mycelium plug placed on the opposite side of the leaflet; i.e., one plug was on the upper epidermis, when the fungicide was treated on the lower epidermis. Colonies were measured and efficacy was calculated as described in the previous paragraph. The experiment was performed twice with 30 replicate leaves per treatment.

Statistical analysis. All data were analyzed using SAS software ver. 8.0. Difference among means was determined with the Duncan's multiple range test at $\mathrm{P}=0.05$.

1. Gianessi, L. \& Reigner, N. The importance of fungicides in U.S. crop production. Outlook Pest Manag. 10, 209-213 (2006).

2. Bartlett, D. W. et al. The strobilurin fungicides. Pest Manag. Sci. 58, 649-662 (2002).

3. Becher, R. \& Wirsel, S. G. R. Fungal cytochrome P450 sterol $14 \alpha$-demethylase (CYP51) and azole resistance in plant and human pathogens. Appl. Microbiol. Biotechnol. 95, 825-840 (2012).

4. Kumar, L. et al. Imidazole derivatives as possible microbicides with dual protection. Eur. J. Med. Chem. 45, 817-824 (2010).

5. Avenot, H. F. \& Michailides, T. J. Progress in understanding molecular mechanisms and evolution of resistance to succinate dehydrogenase inhibiting (SDHI) fungicides in phytopathogenic fungi. Crop Prot. 29, 643-651 (2010).

6. Bridges, B. A. Mutagenicity of captan and related fungicides. Mutat. Res. 32, 3-34 (1975)

7. Hurley, P. M., Hill, R. N. \& Whiting, R. J. Mode of carcinogenic action of pesticides inducing thyroid follicular cell tumors in rodents. Environ. Health Perspect. 106, 437-445 (1998).

8. Clary, T. \& Ritz, B. Pancreatic cancer mortality and organochlorine pesticide exposure in California, 1989-1996. Am. J. Ind. Med. 43, 306-313 (2003)

9. Gordon, E. Captan: Transition from 'B2' to 'not likely'. How pesticide registrants affected the EPA Cancer Classification Update. J. Appl. Toxicol. 27, 519-526 (2007)

10. FRAC, List of plant pathogenic organisms resistant to disease control agents (2013) Available from: http://www.frac.info/publication/anhang/List $\% 20$ of\% 20resistant\%20plant\%20pathogenic\%20organisms_February\% 202013\%20updated.pdf (Date of access: 10/7/2014)

11. Si, N. G. et al. Biological activity and application of a novel fungicide SYP-Z048 (I). Chin. J. Pestic. 43, 16-18 (2004).
12. Han, P., Liu, X., Liu, P. \& Si, N. Effect of novel fungicide 5-(4-chloro phenyl)-2,3dimethyl-3-(pyridine-3)-oxazoline on ergosterol biosynthesis in Botrytis cinerea by high performance liquid chromatography. Chin. J. Anal. Chem. 34, 1467-1470 (2006).

13. Chen, F. P. et al. Baseline sensitivity of Monilinia fructicola from China to the DMI fungicide SYP-Z048 and analysis of DMI-resistant mutants. Plant Dis. 96, 416-422 (2012).

14. Masner, P. \& Kerkenaar, A. Effect of the fungicide pyrifenox on sterol biosynthesis in Ustilago maydis. Pestic. Sci. 22, 61-69 (1988).

15. Aoyama, Y., Yoshida, Y., Hata, S., Nishino, T. \& Katsuki, H. Buthiobate: A potent inhibitor for yeast cytochrome P-450 catalyzing $14 \alpha$-demethylation of lanosterol. Biochem. Biophys. Res. Commun. 115, 642-647 (1983).

16. Zehr, E. I., Luszcz, L. A., Olien, W. C., Newall, W. C. \& Toler, J. E. Reduced sensitivity in Monilinia fructicola to propiconazole following prolonged exposure in peach orchards. Plant Dis. 83, 913-916 (1999).

17. Yoshimura, M. A., Luo, Y., Ma, Z. H. \& Michailides, T. J. Sensitivity of Monilinia fructicola from stone fruit to thiophanate-methyl, iprodione, and tebuconazole. Plant Dis. 88, 373-378 (2004).

18. Shaber, S. H., Zhang, L., Szapacs, E. M. \& Quinn, J. A. Heterocyclic substituted isoxazolidines and their use as fungicides. U.S. Patent 6313147.B1 (2001).

19. Damodiran, M. et al. Antibacterial Activity, Quantitative structure-activity relationship and diastereoselective synthesis of isoxazolidine derivatives via 1,3dipolar cycloaddition of d-glucose derived nitrone with olefin. Chem. Biol. Drug Des. 74, 494-506 (2009).

20. Liu, X.-H., Lv, P.-C., Xue, J.-Y., Song, B.-A. \& Zhu, H.-L. Novel 2,4,5-trisubstituted oxazole derivatives: Synthesis and antiproliferative activity. Eur. J. Med. Chem. 44, 3930-3935 (2009)

21. Turan-Zitouni, G., Kaplancikli, Z. A., Ozdemir, A., Revial, G. \& Guven, K. Synthesis and antimicrobial activity of some 2-(benzod oxazol/benzod imidazol2-ylthio)-N-(9H-fluoren-9-yl)acetamide derivatives. Phosphorus Sulfur Silicon Relat. Elem. 182, 639-646 (2007).

22. Vicentini, C. B. et al. Synthesis and biological evaluation of a series of substituted pyrazolo 3,4-d -1,2,3-triazoles and pyrazolo 3,4-d oxazoles. Arch. Pharm. 331, 269-272 (1998)

23. Bhat, A. R., Athar, F. \& Azam, A. New derivatives of 3,5-substituted-1,4,2 dioxazoles: Synthesis and activity against Entamoeba histolytica. Eur. J. Med. Chem. 44, 926-936 (2009).

24. Xiao, K. H. et al. Effect of famoxadone on photoinduced electron transfer between the iron-sulfur center and cytochrome $\mathrm{cl}$ in the cytochrome bcl complex. J. Biol. Chem. 278, 11419-11426 (2003).

25. Jiang, Y. Effects of oxadixyl treatment on the ultrastructure of Phytophthora infestans infecting tomato leaves. Pestic. Sci. 35, 153-159 (1992).

26. Kataoka, S., Takagaki, M., Kaku, K. \& Shimizu, T. Mechanism of action and selectivity of a novel fungicide, pyribencarb. J. Pestic. Sci. 35, 99-106 (2010).

27. Liu, Z. et al. Dipyrithione inhibits lipopolysaccharide-induced iNOS and COX-2 up-regulation in macrophages and protects against endotoxic shock in mice. FEBS Lett. 582, 1643-1650 (2008)

28. Toquin, V. et al. A new mode of action for fluopicolide: modification of the cellular localization of a spectrin-like protein. Pflanzenschutz-Nachrichten Bayer 59, 171-184 (2006)

29. Sisler, H. D. \& Ragsdale, N. N. [Biochemical and cellular aspects of the antifunga action of ergosterol biosynthesis inhibitors] Mode of action of antifungal agents [257-282] (Cambridge,UK,1984).

30. Buck, J. W. \& Williams-Woodward, J. L. The effect of fungicides on urediniospore germination and disease development of daylily rust. Crop Prot. 22, 135-140 (2003).

31. Obanor, F. O., Walter, M., Jones, E. E. \& Jaspers, M. V. In vitro effects of fungicides on conidium germination of Spilocaea oleagina, the cause of olive leaf spot. N. Z. Plant Prot. 58, 278-282 (2005).

32. Clarkson, J. P., Kennedy, R., Phelps, K., Davies, J. \& Bowtell, J. Quantifying the effect of reduced doses of propiconazole (Tilt) and initial disease incidence on leek rust development. Plant Pathol. 46, 952-963 (1997).

33. Pontzen, R. \& Scheinpflug, H. Effects of triazole fungicides on sterol biosynthesis during spore germination of Botrytis cinerea, Venturia inaequalis and Puccinia graminis f. sp. tritici. Eur. J. Plant Pathol. 95, 151-160 (1989).

34. EPPO/CABI, Data sheets on quarantine pests: Monilinia fructicola. (2010) Available from: https://www.eppo.int/QUARANTINE/fungi/Monilinia fructicola/MONIFC_ds.pdf (Date of access: 11/7/2014).

35. Hong, C., Holtz, B. A., Morgan, D. P. \& Michailides, T. J. Significance of thinned fruit as a source of the secondary inoculum of Monilinia fructicola in California nectarine orchards. Plant Dis. 81, 519-524 (1997).

36. Luo, Y. \& Michailides, T. J. Risk analysis for latent infection of prune by Monilinia fructicola in California. Phytopathology 91, 1197-1208 (2001).

37. Jones, A. L. \& Ehret, G. R. Isolation and characterization of benomyl-tolerant strains of Monilinia fructicola. Plant Dis. 60, 765-769 (1976).

38. Elmer, P. A. G. \& Gaunt, R. E. The biological characteristics of dicarboximideresistant isolates of Monilinia fructicola from New Zealand stone-fruit orchards. Plant Pathol. 43, 130-137 (1994).

39. Amiri, A., Brannen, P. M. \& Schnabel, G. Reduced sensitivity in Monilinia fructicola field isolates from South Carolina and Georgia to respiration inhibitor fungicides. Plant Dis. 94, 737-743 (2010). 
40. Harada, Y. et al. Monilia mumecola, a new brown rot fungus on Prunus mume in Japan. J. Gen. Plant Pathol. 70, 297-307 (2004).

41. Valencia-Chamorro, S. A., Perez-Gago, M. B., Del Rio, M. A. \& Palou, L. Curative and preventive activity of hydroxypropyl methylcellulose-lipid edible composite coatings containing antifungal food additives to control citrus postharvest green and blue molds. J. Agric. Food Chem. 57, 2770-2777 (2009).

\section{Acknowledgments}

This work was supported by the Special Fund for Agroscientific Research in the Public Interest of China (201303023). This work was also partially supported by National High Technology Research and Development Program of China (2012CB111401). We thank J. L. Starr for his editorial efforts and critique on the manuscript.

\section{Author contributions}

L.X. and C.F. designed the experiments. C.F. and H.P. performed the experiments in vitro. S.N. and L.J. performed the experiments in field. C.F. and L.P. interpreted the results. L.X. and C.F. wrote the paper. All authors reviewed the manuscript.

\section{Additional information}

Competing financial interests: The authors declare no competing financial interests.

How to cite this article: Chen, F. et al. Activity of the novel fungicide SYP-Z048 against plant pathogens. Sci. Rep. 4, 6473; DOI:10.1038/srep06473 (2014).

(c) (i) (2) This work is licensed under a Creative Commons Attribution-NonCommercialShareAlike 4.0 International License. The images or other third party material in this article are included in the article's Creative Commons license, unless indicated otherwise in the credit line; if the material is not included under the Creative Commons license, users will need to obtain permission from the license holder in order to reproduce the material. To view a copy of this license, visit http:// creativecommons.org/licenses/by-nc-sa/4.0/ 